\title{
Simultaneous determination of albendazole and praziquantel in rat plasma by HPLC-UV
}

\author{
Shreya Shah ${ }^{2}$, Suddhasattya Dey ${ }^{1 *}$, Kamal Kant ${ }^{1}$, Padma Charan Behera ${ }^{1}$ and Manik Ghosh ${ }^{1^{*}}$ \\ ${ }^{1}$ Birla Institute of Technology, Mesra, Ranchi, Jharkhand (835215), India \\ ${ }^{2}$ Sigma Institute of Pharmacy, Vadodara, Gujarat (390016), India \\ Email:manik@bitmesra.ac.in
}

\begin{abstract}
A simple, sensitive, and easy high-performance liquid chromatographic [HPLC] method has been developed and validated for the simultaneous estimation of albendazole [ABZ] and praziquantel [PRQ] using diazepam as an internal standard in rat plasma. Extraction of $A B Z, P R Q$ and Diazepam in rat plasma was carried out by a process which involves precipitation of proteins called protein precipitation. Protein precipitation method was done by using $8.25 \%$ perchloric acid. Chromatographic separations were performed using an Enable C18 column [250 $\mathrm{mm} \times 4.6 \mathrm{~mm}, 5 \mu \mathrm{m}$ : Spinco Biotech Pvt. Ltd]. The mobile phase consisted of acetonitrile: water [60:40, V/V] at a flow rate of $1.0 \mathrm{~mL} \mathrm{min-1}$ at an ambient temperature for plasma samples. The above method was developed and validated over the range from 50-8000 $\mathrm{ng} / \mathrm{mL}$ for both $A B Z$ and $P R Q$ in the rat plasma. The recovery of $A B Z$ was found to be 97.81 to $105.28 \%$, whereas $P R Q$ recoveries ranged from 96.80 to $102.63 \%$ in the rat plasma. Acceptable Intra- and inter-day assay precision [<15\% R.S.D.] and accuracy [<15\% R.S.D.] were observed over 50-8000 $\mathrm{ng} / \mathrm{mL}$ for $A B Z$ and $P R Q$ in rat plasma. This method can be effectively applied to the pharmacokinetic study of albendazole and praziquantel in rat plasma to determine all the pharmacokinetic parameters.
\end{abstract}

Keywords: Albendazole; Praziquantel; Validation; Bioanalytical; HPLC

\section{INTRODUCTION}

The most common helminthic disease of the nervous system is nee is the most common helminthic disease of the nervous system, is neurocysticercosis, which is considered as a serious public health problem in developing countries of Latin America, Asia and Africa [13]. The use of both the drugs Albendazole [ABZ] and Praziquantel [PRQ] consider an effective against the cystic larvae for the treatment of neurocysticercosis over the last 20 years with the use of both the drugs ABZ \& PRQ. ABZ has been found an effective drug of choice than PRQ, but this persistence of cysts even after continuous use of ABZ [2]. For the patients, who were the persistence of cyst after the use of ABZ, an alternative treatment therapy was developed where there was simultaneous use of PRQ and ABZ has been evaluated [4-5]. Albendazole and Praziquantel in combination were used extensively for human hydatid disease [6-9]. Albendazole [ABZ] is an inactive moiety but it readily gets metabolized to an active metabolite Albendazole sulfoxide [ABZSO] then this ABZSO is then further metabolized to an inactive metabolite Albendazole sulfone [ $\left.\mathrm{ABZSO}_{2}\right]$ [10]. As $\mathrm{ABZ}$ is metabolized extensively, therefore, the plasma concentration of $\mathrm{ABZ}$ is also very low as a result the pharmacokinetic studies were been done using Albendazole sulfoxide [ABZSO] as an active metabolite and Albendazole sulfone $\left[\mathrm{ABZSO}_{2}\right]$ as an inactive metabolite [11-15]. Metabolism of Praziquantel [PRQ] occurs giving a number of hydroxylated metabolites [16-18], among which the active metabolite is mainly trans-4hydroxypraziquantel [TRANS], an active metabolite [19]. Evaluation and the determination of various pharmacokinetic parameters of ABZ and PRQ, the method has been developed 
which is simple, selective and sensitive analytical method for Limit of Quantitation [LOQ] determination in plasma samples for different metabolites. A number of High-performance liquid chromatographic [HPLC] system [20-29] and capillary electrophoresis methods [CE] [30-31] has been developed for the estimation of ABZ \& PRQ. A recent advances method has been developed for the estimation of $\mathrm{ABZ}, \mathrm{ABZSO}, \mathrm{ABZSO}_{2}$ \& PRQ in trans form by tandem mass spectrophotometry [LC-MS/MS]. By using this technique, the analysis of ABZ and PRQ along with their metabolites has been isolated [32] and [33] by the use of LCMS/MS for the development of two methods with Limit of Quantitation [LOQ] for ABZSO were 5.0 and $3.7 \mathrm{ng} / \mathrm{mL}$, respectively. Further, method which reported a Limit of Quantitiation of $0.5 \mathrm{ng} / \mathrm{mL}$ for ABZSO an active metabolite of ABZ [32]. LC-MS/MS method was only used for the qualitative analysis of PRQ metabolites [16 \& 34]. There is only one method available for simultaneous determination of albendazole metabolites, praziquantel and its metabolite in plasma by high-performance liquid chromatographyelectrospray mass spectrometry [35] which is a costly method but sensitive.

For the first time a high sensitive, simple HPLC assay method was developed for the simultaneous estimation of ABZ and PRQ in rat plasma along with an as an internal standard [Diazepam], which is a cost-effective and sensitive enough to determine the concentration in nanogram level.

\section{MATERIAL AND METHODS}

\subsection{Chemicals and Reagents}

Albendazole [Figure1a] was obtained from Mercury Labs Ltd, Vadodara, India, Praziquantel [Figure1b] was obtained from Micro Labs Ltd., Goa, India and Diazepam [Figure 1c] was obtained from Hetro Pharma Ltd. Hyderabad, India as a gift samples. Acetonitrile, Methanol and Water [obtained from S. D. Fine Chemicals Limited, Worli, Mumbai, India.] of HPLC grade were used. The other reagents [Perchloric acid and Ortho Phosphoric acid] used for the development of the liquid chromatographic method for determination of albendazole and praziquantel in rat plasma were of analytical grade obtained from Merck Specialties private limited, Worli, Mumbai, India.<smiles>CCCSc1ccc2[nH]c(NC(=O)OC)nc2c1</smiles>

Fig 1(a). Chemical structure of albendazole<smiles>O=C(C1CCCCC1)N1CC(=O)N2CCc3ccccc3C2C1</smiles>

Fig 1(b). Chemical structure of praziquantel<smiles>CN1C(=O)CN=C(c2ccccc2)c2cc(Cl)ccc21</smiles>

Fig 1(c). Chemical structure of Diazepam (Internal Standard) 


\subsection{Chromatography}

A high-performance liquid chromatography [Shimadzu, Kyoto, Japan] was composed of an LC-20AT Prominence solvent delivery module, a manual rheodyne injector with a $20-\mu \mathrm{L}$ fixed loop and an SPD-20A Prominence UV-visible detector. Separation was performed on an Enable C18G column [Column Length: $250 \mathrm{~mm} \times 4.6 \mathrm{~mm}$ i.d.; $5 \mu \mathrm{m}$; particle size, Enable] at an ambient temperature. The data acquisition was made with Spinchrom Chromatographic Station ${ }^{\circledR}$ CFR Version 2.4.195 [Spinchrom Pvt. Ltd., Chennai, India]. The mobile phase consisted of acetonitrile/water [60:40, V/V] solution adjusted to $\mathrm{pH} 3.2$ with $10 \%$ orthophosphoric acid for plasma samples at a flow rate of $1.0 \mathrm{~mL} / \mathrm{min}$. U. V. scan [Spectro Analytical 2080, Software: UV-Vis Analyst] was performed at a concentration of 6000 ng/mL for ABZ, PRQ, and mixture using methanol as a blank shown in Figure 2 and UV detection was set at $225 \mathrm{~nm}$ for both $\mathrm{ABZ}$ and PRQ respectively.

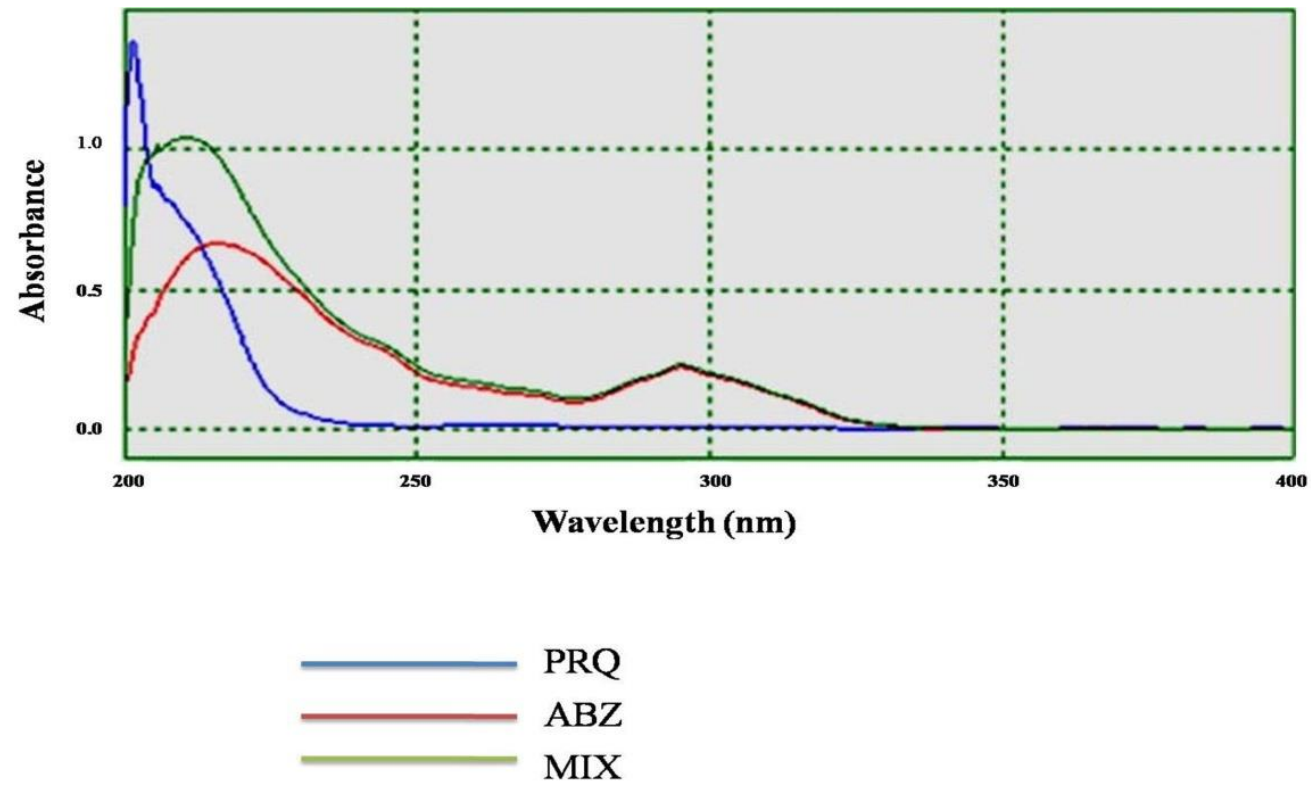

Fig 2. U.V. Spectra of ABZ \& PRQ mixture (6000 ng/ml)

\subsection{Preparation of stock and standard solutions}

A stock solution of $1 \mathrm{mg} / \mathrm{ml}$ of albendazole, praziquantel and diazepam were prepared using methanol. Standard solution of ABZ, PRQ, and Diazepam [I.S.] were prepared from the stock solution using methanol for the dilution, of appropriate amounts taking from individual stock solution by methanol. Finally, the different concentration of the standard solution were 80000, 70000, 60000, 50000, 40000, 30000, 20000, 10000, 5000, 1000 and $500 \mathrm{ng} / \mathrm{mL}$ along with a fixed concentration of the internal standard [5000 $\mathrm{ng} / \mathrm{mL}]$. Precision and accuracy standards with concentrations of $80000,40000,50000$ and $500 \mathrm{ng} / \mathrm{mL}$ were also prepared in the same manner along with a fixed concentration of the internal standard [5000 ng/mL]. All the stock solutions were prepared and refrigerated, which was not used and are replaced on a weekly basis. In every day, fresh standard solution was prepared for analysis and validation purpose.

\subsection{Sample Collection}

The use of animals in this study was approved by CPCSEA [Committee for the Purpose of Control and Supervision on Experimental Animals]. The rats were housed one animal per cage at Animal House of Sigma Institute of Pharmacy, Baroda. The environment was controlled with daily feeding and water. 
Healthy albino rats [weighing 150-250 gm] venous blood samples [2 $\mathrm{mL}$ ] were collected into in $2 \mathrm{~mL}$ heparinized-coated micro-centrifuge tube from retro-orbital plexus of albino rats. The $2 \mathrm{~mL}$ microcentrifuge tube containing blood was centrifuged at $15000 \mathrm{rpm}$ for $15 \mathrm{~min}$ and the plasma was collected carefully. The collected plasma was stored in $-20^{\circ} \mathrm{C}$ till it was used. The blood sample was collected on a regular basis from different rats and plasma was separated till the study was being completed so that the analysis should be unbiased in nature.

\subsection{Sample Preparation}

The plasma samples were treated with protein precipitating agent for the analysis of $A B Z$ and PRQ. To each $400 \mu \mathrm{L}$ plasma spiked with ABZ, PRQ and diazepam of different concentration were taken in $1.5 \mathrm{~mL}$ microcentrifuge tubes and simultaneously a blank [400 $\mu \mathrm{L}$ of plasma without ABZ, PRQ, and Diazepam] was also taken in $1.5 \mathrm{~mL}$ micro-centrifuge tubes. Different protein precipitating agents were used such as ammonia sulfate, 10-15 trichloroacetic acid, $10 \%$ sodium tungstate in water, 5-sulphosalicylic acid, zinc sulfate in methanol, different ratios of organic solvents [Acetone, Acetonitrile, Methanol] and different percentages of perchloric acid in water. Lastly, it was found that $8.25 \%$ of perchloric acid gave a clear chromatogram without any interference with the two analytes [ABZ and PRQ] and internal standard so $8.25 \%$ of perchloric acid was chosen to be used as a protein precipitating agent to precipitate proteins throughout the whole Bioanalytical study.

\subsection{Calibration Curves}

Blank plasma was collected from untreated anesthetized animals. The plasma calibration point was prepared by spiking $400 \mu \mathrm{L}$ of plasma with $40 \mu \mathrm{L}$ of each ABZ, PRQ and Diazepam standard solution and vortex for a few minutes. The calibration curves for rat plasma were in the range of $50-8000 \mathrm{ng} / \mathrm{mL}$ and fixed concentration of the internal standard $[500 \mathrm{ng} / \mathrm{mL}]$. After plasma was spiked, it was subjected to further sample preparation before analysis.

\subsection{System suitability}

System suitability is an integral part of chromatographic analysis. This system suitability test is used to verify the data for Theoretical Plate [N], Height Equivalent to a theoretical plate [HETP], resolution etc which is very much useful for the chromatographic system to pass the minimum limit.

\subsection{Validation of the method}

The developed method was validated by evaluating recovery, linearity, precision, accuracy, quantitation limit and stability. Coefficients of variation and relative errors of less than $15 \%$ were considered acceptable, except for the quantitation limit, for which these values were established at $20 \%$, as recommended in the literature [36-38].

\subsubsection{Linearity}

The linearity was tested in the concentration range of $8000,7000,6000,5000,4000,3000$, $2000,1000,500,100$ and 50ng/mL for both the drugs with a fixed concentration of Diazepam [500ng/mL] and the calibration curve was constructed and evaluated by its correlation coefficient. The linear regression equation was calculated by the least squares method using Microsoft Excel® program.

\subsubsection{Accuracy}

Accuracy of the method was determined by replicate analysis of five sets of samples spiked with four different levels of ABZ and PRQ [50, 4000, 5000, and $8000 \mathrm{ng} / \mathrm{mL}$ ] with a fixed 
concentration of Diazepam [500 $\mathrm{ng} / \mathrm{mL}]$ and comparing the difference between the spiked value [theoretical value] and that actually found value.

\subsubsection{Precision}

The precision of the method based on within-day repeatability was determined by replicate analysis of five sets of samples spiked with four different concentrations of ABZ and PRQ [50, 4000, 5000, and $8000 \mathrm{ng} / \mathrm{mL}]$ with a fixed concentration of Diazepam [500 ng/mL]. The reproducibility [day-to-day variation] of the method was validated using the same concentration range of plasma as described above, but only a single determination of each concentration was made in three different days. Relative standard deviations [R.S.D.] were calculated from the ratios of standard deviation [S.D.] to the mean and expressed as a percentage.

\subsubsection{Recovery}

The analytical recovery of sample preparation procedure for ABZ and PRQ and the internal standard [Diazepam] were estimated by comparing the peak heights obtained from samples [plasma] prepared as described in Section 2.5, with those measured with equivalent amounts of ABZ and PRQ in methanol. The triplicate analysis was performed at concentrations of 50 and $8000 \mathrm{ng} / \mathrm{mL}$ for ABZ and PRQ and at a concentration of $500 \mathrm{ng} / \mathrm{mL}$ of the internal standard.

\subsubsection{Selectivity}

The selectivity of the method was verified by checking for interference by albendazole, albendazole sulphoxide [active metabolite of albendazole], ivermectin, including the commonly used antibiotics ampicillin, penicillin, and gentamycin after subjecting them to sample preparation procedures. Albendazole and ivermectin are antiparasitic drugs which are used in combination with praziquantel in the control of filariasis and geohelminths.

\subsubsection{Limit of Quantitation [LOQ] and Limit of Detection [LOD]:}

The limit of quantitation [LOQ] of the assay procedure was determined from the lowest concentration of $\mathrm{ABZ}$ and PRQ [in spiked plasma sample] that produced a peak height three times the baseline noise at a sensitivity of 0.005 aufs [absorbance unit full scale] in a $400 \mu \mathrm{L}$ sample.

The detection limit of an individual analytical procedure is the lowest amount of analyte in a sample, which can be detected but not necessarily quantitation as an exact value.

\subsubsection{Stability}

The stability of ABZ and PRQ was determined by storing spiked plasma samples [at the concentrations of 50,5000, and $8000 \mathrm{ng} / \mathrm{mL}$ with a fixed concentration of Diazepam [500ng/mL]; triplicate analysis for each concentration] in a $-20^{\circ} \mathrm{C}$ freezer [Sanyo, Japan] for 6 months. Concentrations were measured periodically [ $1^{\text {st }}, 2^{\text {nd }}, 4^{\text {th }}$ and $6^{\text {th }}$ months $]$. To freeze and thaw stability, samples were frozen at $-20^{\circ} \mathrm{C}$ for at least $24 \mathrm{~h}$ and thawed unassisted at room temperature $\left[25^{\circ} \mathrm{C}\right]$. When completely thawed, the samples were transferred back to the original freezer and refrozen for at least $24 \mathrm{~h}$. The process was repeated for three cycles.

\subsection{Quality control}

Quality control [QC] samples for ABZ and PRQ were made up in plasma using a stock solution separated from that used to prepare the calibration curve, at the concentrations of 50 , 4000, 5000 and $8000 \mathrm{ng} / \mathrm{mL}$ along with a fixed concentration of Diazepam [500 ng/mL]. 
Samples were aliquoted into cryovials and stored frozen at $-20^{\circ} \mathrm{C}$ for use with each analytical run. The results of the QC samples provided the basis for accepting or rejecting the run. At least, two of the four QC samples had to be within $\pm 20 \%$ of their respective nominal value. Two of the four QC samples could be outside the $\pm 20 \%$ of their respective nominal value, but not at the same concentration.

\section{RESULTS AND DISCUSSION}

\subsection{Sample preparation}

The sample preparation step used in this study involved protein precipitation of the sample, i.e., perchloric acid is used to precipitate the proteins from plasma [8.25\% of perchloric acid]. To each $400 \mu \mathrm{L}$ of plasma spiked sample was mixed with $45 \mu \mathrm{L}$ of $8.25 \%$ perchloric acid for 30 seconds. The samples were centrifuged at $12000 \mathrm{rpm}$ for $15 \mathrm{~min}$ this gives a clear supernatant liquid at the top in comparison to all other protein precipitating agents mentioned in section 2.5. $20 \mu \mathrm{L}$ of clear supernatant liquid was transferred in Hamilton Syringe and injected through the rheodyne injector to HPLC column for analysis. This condition was found to be the most optimal conditions for sample preparation as it resulted in a clean chromatogram.

\subsection{Chromatographic separation}

A number of HPLC chromatographic systems were investigated to optimize the separation of ABZ, PRQ and Diazepam. Retention time for ABZ, PRQ and Diazepam function using stationary phase [Enable $\mathrm{C} 18$ reversed-phase column] and the mobile phase acetonitrile and distilled water in the ratio of $60: 40[\mathrm{v} / \mathrm{v}]$ with $\mathrm{pH} 3.2$ were 3.7, 6.4 and $8.5 \mathrm{~min}$. The chromatograms showed a good baseline. Chromatogram of ABZ, PRQ, and Diazepam [internal standard] is shown in Figure 3.

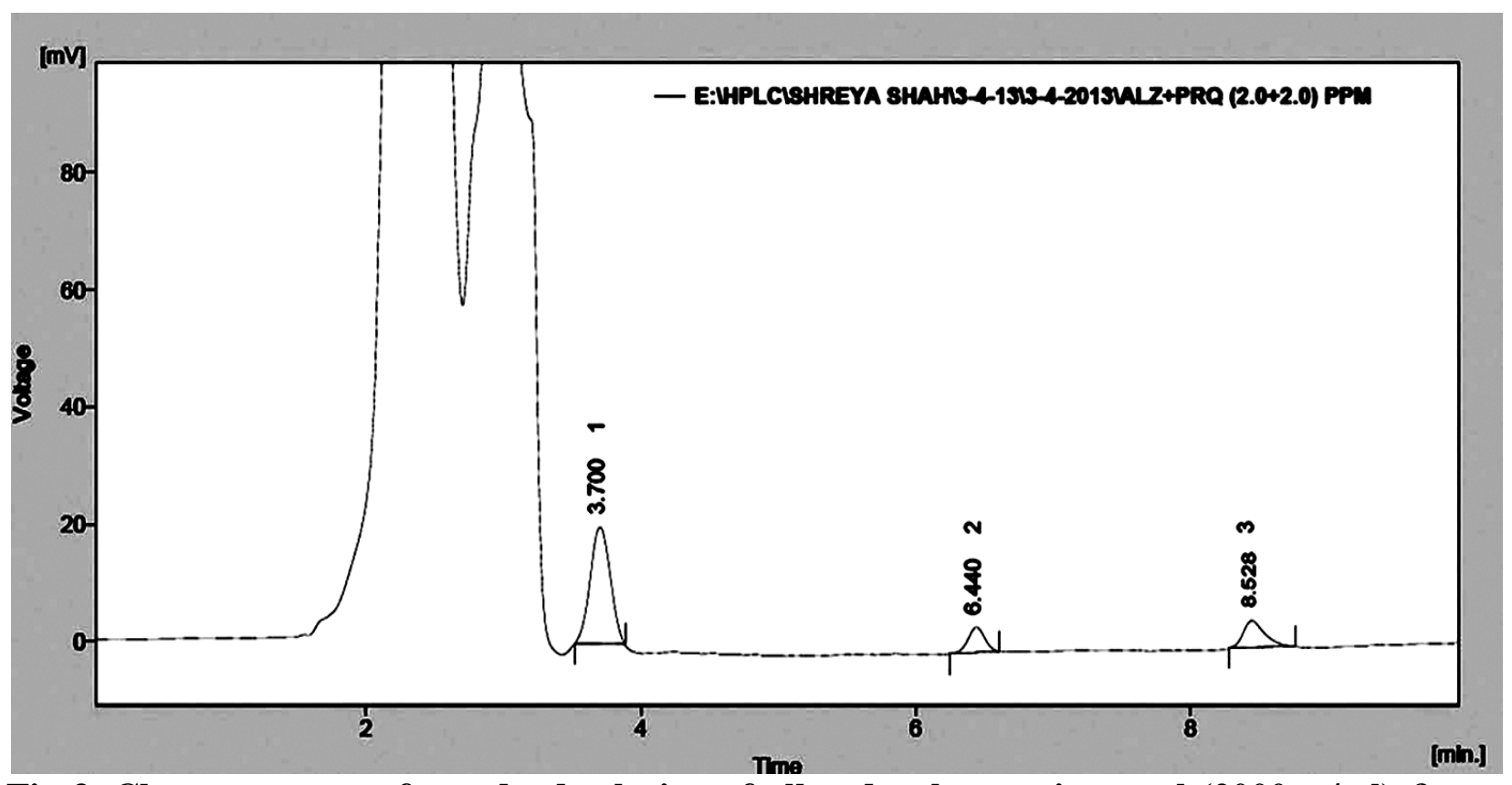

Fig 3. Chromatogram of standard solution of albendazole, praziquantel $(2000 \mathrm{ng} / \mathrm{ml}) \&$ diazepam $(500 \mathrm{ng} / \mathrm{ml})$ in plasma with retention times of $3.7,6.4 \& 8.5$.

\subsection{Calibration curves}

Plasma analysis was calibrated using the concentration range of $50-8000 \mathrm{ng} / \mathrm{mL}$ for both ABZ and PRQ with a fixed concentration of Diazepam [500ng/mL]. The calibration curves 
for ABZ and PRQ were considered linear for the evaluated concentrations. The linear regression equations and correlation coefficients $[\mathrm{r}]$ were as follow: $\mathrm{ABZ}, \mathrm{Y}=0.004 \mathrm{X}+0.016$ $[\mathrm{r}=0.999]$ and $\mathrm{PRQ}, \mathrm{Y}=0.0005 \mathrm{X}+0.233[\mathrm{r}=0.999]$.

\subsection{System suitability}

System suitability tests, an integral part of a chromatographic analysis was used to verify that the resolution and reproducibility of the chromatographic system are adequate for the analysis [39]. A system suitability test according to USP was performed on the chromatograms obtained from standard and test solutions to check different above-mentioned parameters and the results obtained from six replicate injections of the standard solution are summarized in Table 1.

Table 1: System suitability parameters for ABZ, PRQ and Diazepam

\begin{tabular}{|lllll|}
\hline S. No. & Parameters & $\begin{array}{l}\text { ABZ } \\
(\mathrm{min})\end{array}$ & $\begin{array}{l}\text { PRQ } \\
(\mathrm{min})\end{array}$ & $\begin{array}{l}\text { Diazepam } \\
(\mathrm{min})\end{array}$ \\
\hline 1. & Retention time, Rt (min) & $3.7 \mathrm{~min}$ & $6.4 \mathrm{~min}$ & $8.5 \mathrm{~min}$ \\
2. & Retention factor $\left(k^{\prime}\right)$ & 1.341 & 3.07 & 4.39 \\
3. & Separation factor $(\alpha)$ & 2.289 & 1.42 & ------- \\
4. & Number of Theoretical plates (USP) & 2433.77 & 7281.77 & 12844.44 \\
5. & HETP $(\mathrm{mm})$ & 0.102 & 0.034 & 0.019 \\
6. & Resolution $(\mathrm{Rs})$ & 3.9 & 4.71 & -------- \\
\hline
\end{tabular}

\subsection{Method validation}

\subsubsection{Linearity}

The linearity was tested in the concentration range of 8000, 7000, 6000, 5000, 4000, 3000, $2000,1000,500,100$ and 50ng/mL for both the drugs with a fixed concentration of Diazepam [500ng/mL] and the calibration curve was constructed and evaluated by its correlation coefficient. The linear regression equation was calculated by the least squares method using Microsoft Excel ${ }^{\circledR}$ program. The coefficient of determination $\left[\mathrm{r}^{2}\right]$ for ABZ and PRQ in plasma was found to be 0.994 and 0.995 indicating a strong linear relationship between the variable summarized in Table 2.

Table 2: Spectral and statistical data for determination of ABZ \& PRQ by the proposed HPLC method

\begin{tabular}{|lll|}
\hline Parameters & Value for ABZ & Value for PRQ \\
\hline Absorption maxima, $\lambda \max (\mathrm{nm})$ & $217 \mathrm{~nm}$ & 294.5 \\
Linearity range $(\mathrm{ng} / \mathrm{mL})$ & $50-8000$ & $50-8000$ \\
Coefficient of determination $\left(\mathrm{r}^{2}\right)$ & 0.994 & 0.995 \\
Correlation coefficient $(\mathrm{r})$ & 0.999 & 0.999 \\
Regression equation $\left(\mathrm{Y}^{\mathrm{a}}\right)$ & $\mathrm{Y}=0.004 \mathrm{x}+0.016$ & $\mathrm{Y}=0.0005 \mathrm{x}+2.333$ \\
Slope $(\mathrm{b})$ & 0.004 & 0.000 \\
Intercept (a) & 0.016 & 2.333 \\
Limit of quantitation, LOQ $(\mathrm{ng} / \mathrm{mL})$ & 50 & 50 \\
Limit of detection, LOD $(\mathrm{ng} / \mathrm{mL})$ & 15.15 & 15.15 \\
\hline
\end{tabular}

${ }^{\mathrm{a}} Y=\mathrm{mx}+\mathrm{c}$, where $x$ is the concentration $(\mathrm{ng} / \mathrm{mL})$. 
[For minimum error with precise, concise and accurate data 11 different concentrations were being taken which gave a wide range of linearity. The coefficient of determination $\left[\mathrm{r}^{2}\right]$ for plasma is 0.994 and 0.995 for both ABZ and PRQ are given in Figure 4 and 5 respectively. Included in the results]

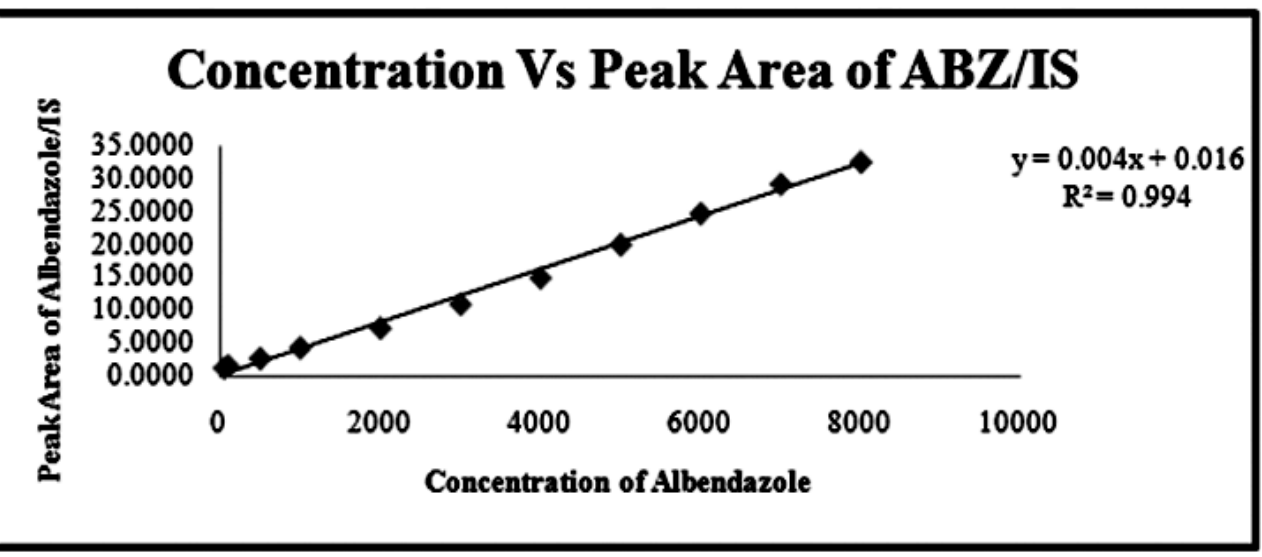

Fig 4. Calibration curve of albendazole in rat plasma

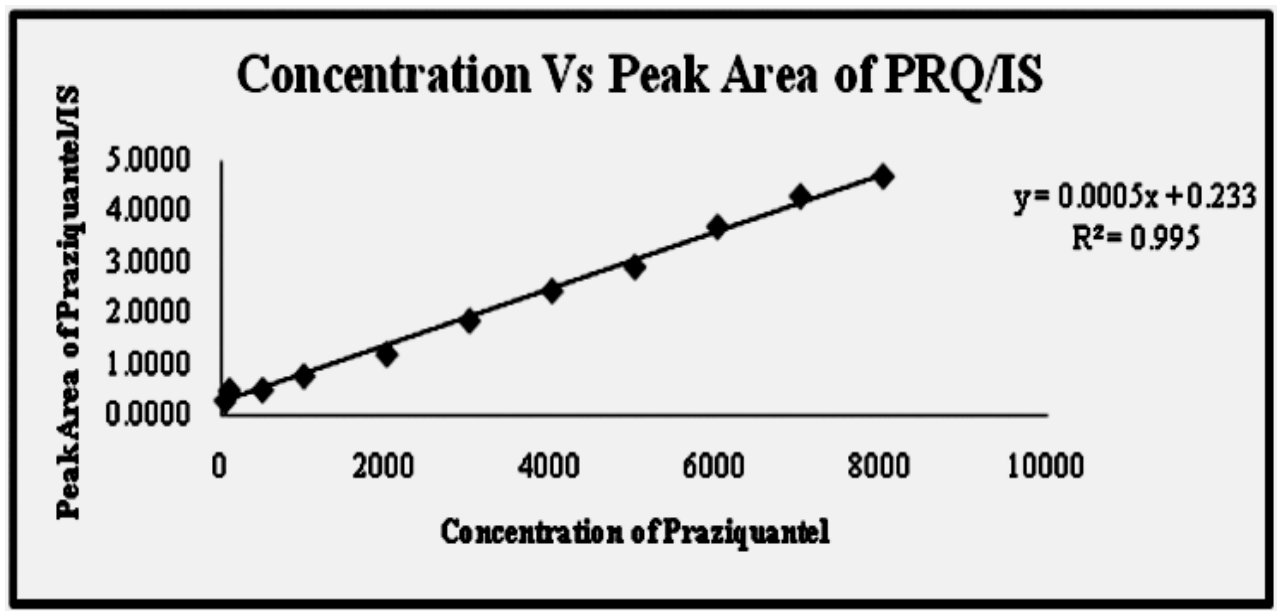

Fig 5. Calibration curve of praziquantel in rat plasma

\subsubsection{Precision}

Inter-day of ABZ and PRQ gave an R.S.D. within 6.0 and 10.2 inter-assay [day-to-day] variation for $A B Z$ and $P R Q$ assay at the concentration range 50-8000 ng/mL [50, 4000, 5000 and $8000 \mathrm{ng} / \mathrm{mL}]$.

Intra-day of ABZ and PRQ, gave an R.S.D. within 1.8 and 11.4 The intra-assay [within-day] for ABZ and PRQ assay at the concentration range 50-8000 ng/mL [50, 4000, 5000 and $8000 \mathrm{ng} / \mathrm{mL}$ ] [should be less than $15 \%$ according to CDER guidance for Bioanalytical Method Validation [CDER, 2000]], revealed that the proposed method is highly precise. Little variation of $\mathrm{ABZ}$ and $\mathrm{PRQ}$ assays was observed; relative standard deviation [R.S.D.] for all four different concentrations of $\mathrm{ABZ}$ and PRQ observed was all below 15\% are summarized in Table 3. 
Table 3: Inter-day (within run precision) $(n=5)$ and Intra-day (between run precision) $(n=5)$ precision (\%R. S. D.) measured for QC points for ABZ \& PRQ in rat plasma.

\begin{tabular}{|llllllllll|}
\hline \multirow{2}{*}{ ABZ } & T.C. & \multicolumn{2}{c}{ Day 1 } & \multicolumn{2}{c}{ Day 2 } & \multicolumn{2}{c|}{ Day 3 } & \multicolumn{2}{c|}{ Intra-day } \\
\cline { 3 - 11 } Plasma & ng/mL & E.C. & \%R.S.D. & E.C. & \% R.S.D. & E.C. & \%R.S.D. & E.C. & \%R.S.D. \\
\hline 1 & 8000 & 8093.55 & 0.71687 & 8072.12 & 0.65004 & 8177.26 & 0.33087 & 8182.72 & 0.57035 \\
2 & 5000 & 4954.98 & 0.65986 & 5056.24 & 0.93902 & 5177.17 & 0.59228 & 4890.95 & 0.41316 \\
3 & 4000 & 4067.35 & 1.52935 & 4042.63 & 1.98893 & 4048.04 & 0.65112 & 4058.79 & 0.87712 \\
4 & 50 & 53.202 & 6.08963 & 52.787 & 1.28777 & 51.5094 & 1.59543 & 52.642 & 1.82865 \\
\hline PRQ & T.C. & \multicolumn{2}{c}{ Day 1 } & \multicolumn{1}{c}{ Day 2 } & & Day 3 & Intra-day \\
Plasma & ng/mL & E.C. & \%R.S.D. & E.C. & \%R.S.D. & E.C. & \%R.S.D. & E.C. & \%R.S.D. \\
\hline 1 & 8000 & 7918.83 & 0.55579 & 8161.02 & 0.55192 & 8046.85 & 0.07982 & 8115.63 & 0.69539 \\
2 & 5000 & 5025.06 & 0.98497 & 5020.16 & 1.17303 & 5022.43 & 1.02524 & 4995.02 & 1.70992 \\
3 & 4000 & 4019.31 & 0.74296 & 4021.52 & 3.04784 & 3959.55 & 1.04539 & 4105.32 & 0.84527 \\
4 & 50 & 51.1988 & 10.2658 & 51.5233 & 7.33696 & 48.7074 & 8.36071 & 48.4009 & 11.4739 \\
\hline
\end{tabular}

T.C. denotes theoretical concentration and E.C. denotes experimental concentration.

\subsubsection{Accuracy and Recovery}

Accuracy data in the present study ranged from 97.81 to $105.28 \%$ for ABZ and 96.80 to $102.63 \%$ for PRQ [Table 4] indicates that there was no interference from endogenous plasma components. Inter-day as well as intra-day range $50-8000 \mathrm{ng} / \mathrm{mL}$ along with a fixed concentration of Diazepam 500ng/mL [50, 4000, 5000 and $8000 \mathrm{ng} / \mathrm{mL}]$. The mean recoveries for ABZ and PRQ in plasma at the concentration range 50-8000 ng/mL were found to be greater than $90 \%$. The results reflect essentially nearly $100 \%$ recovery from the spiked plasma and indicate a lack of interference from the sample preparation procedure.

Table 4: Summary of inter-day (within run precision) $(n=5)$ and intra-day (between run precision) $(n=5)$ precision and accuracy of the method in rat plasma

\begin{tabular}{|c|c|c|c|c|c|}
\hline Analyte & $\begin{array}{l}\text { Nominal } \\
\text { concentration }\end{array}$ & $\begin{array}{l}\text { Mean } \\
\text { concentration }\end{array}$ & S.D. & Precision & $\begin{array}{c}\text { Mean } \\
\text { accuracy b }\end{array}$ \\
\hline $\mathbf{A B Z}$ & $(\mathbf{n g} / \mathbf{m L})$ & Found a $(\mathbf{n g} / \mathbf{m L})$ & & (\%R.S.D.) & $(\%)$ \\
\hline \multicolumn{6}{|c|}{ Intra-day $(n=5)$} \\
\hline & 8000 & 8182.7238 & 46.6 & 0.570350 & 101.27 \\
\hline & 5000 & 4890.9502 & 20.2 & 0.413161 & 97.81 \\
\hline & 4000 & 4058.7924 & 35.6 & 0.877123 & 101.46 \\
\hline & 50 & 52.642 & 0.96 & 1.828648 & 105.28 \\
\hline \multicolumn{6}{|c|}{ Inter-day $(\mathrm{n}=5)$} \\
\hline & 8000 & 8114.3148 & 45.8 & 0.565932 & 101.27 \\
\hline & 5000 & 5062.7956 & 36.9 & 0.730389 & 101.25 \\
\hline & 4000 & 4052.672933 & 56.3 & 1.389802 & 101.31 \\
\hline & 50 & 52.49946667 & 1.58 & 2.990941 & 104.99 \\
\hline
\end{tabular}




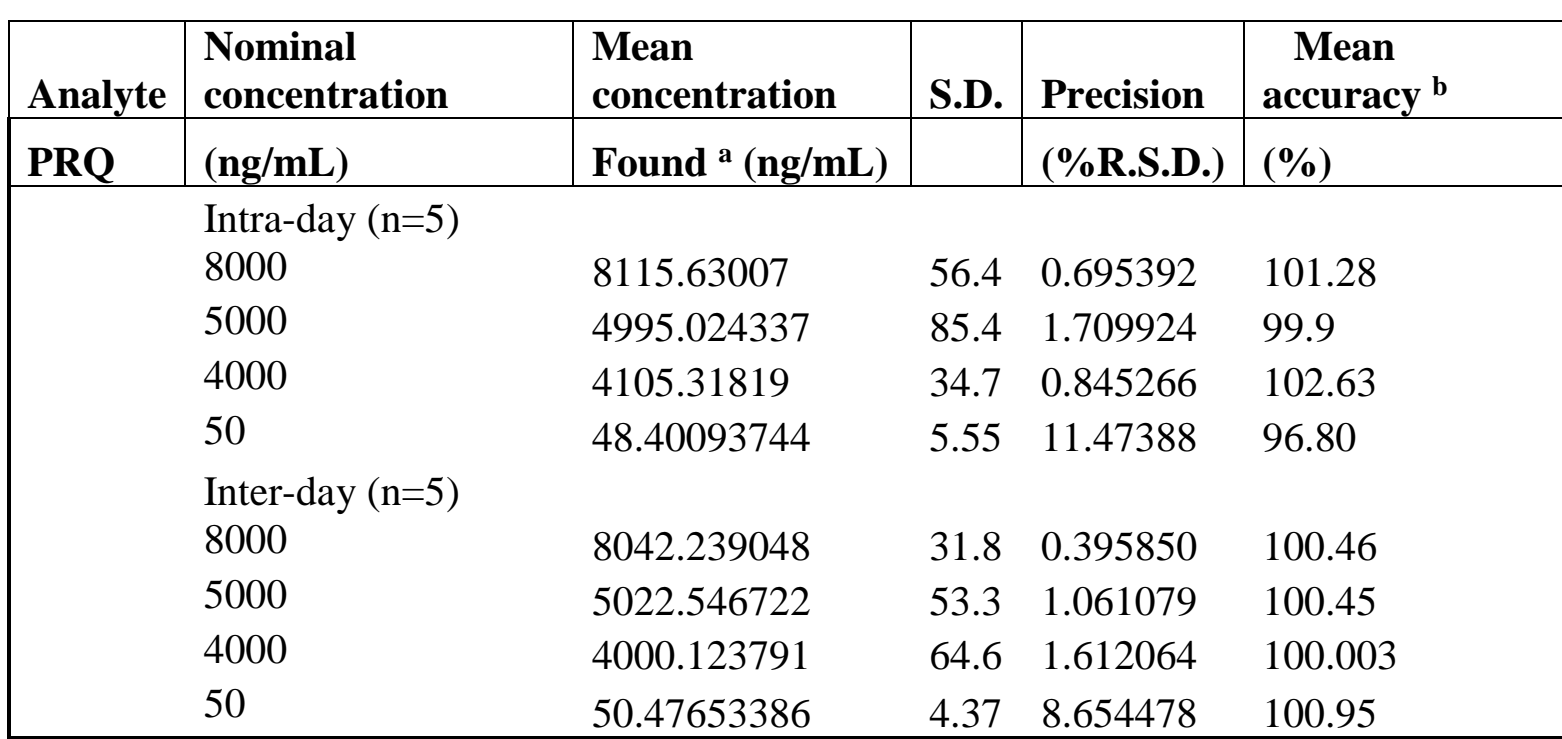

${ }^{a}$ Average of three and six determinations at three concentration levels for inter-day and intra-day respectively.

${ }^{b}$ All the mean accuracies were calculated against their nominal concentrations.

\subsubsection{Selectivity}

Selectivity of the chromatographic separation was demonstrated by the absence of interferences from endogenous peaks in plasma. Figure 6 and Fig 7 illustrates typical chromatograms for spiked plasma and blank plasma, with ABZ, PRQ, and Diazepam with the retention time of $3.7,6.4$ and 8.5 minutes.

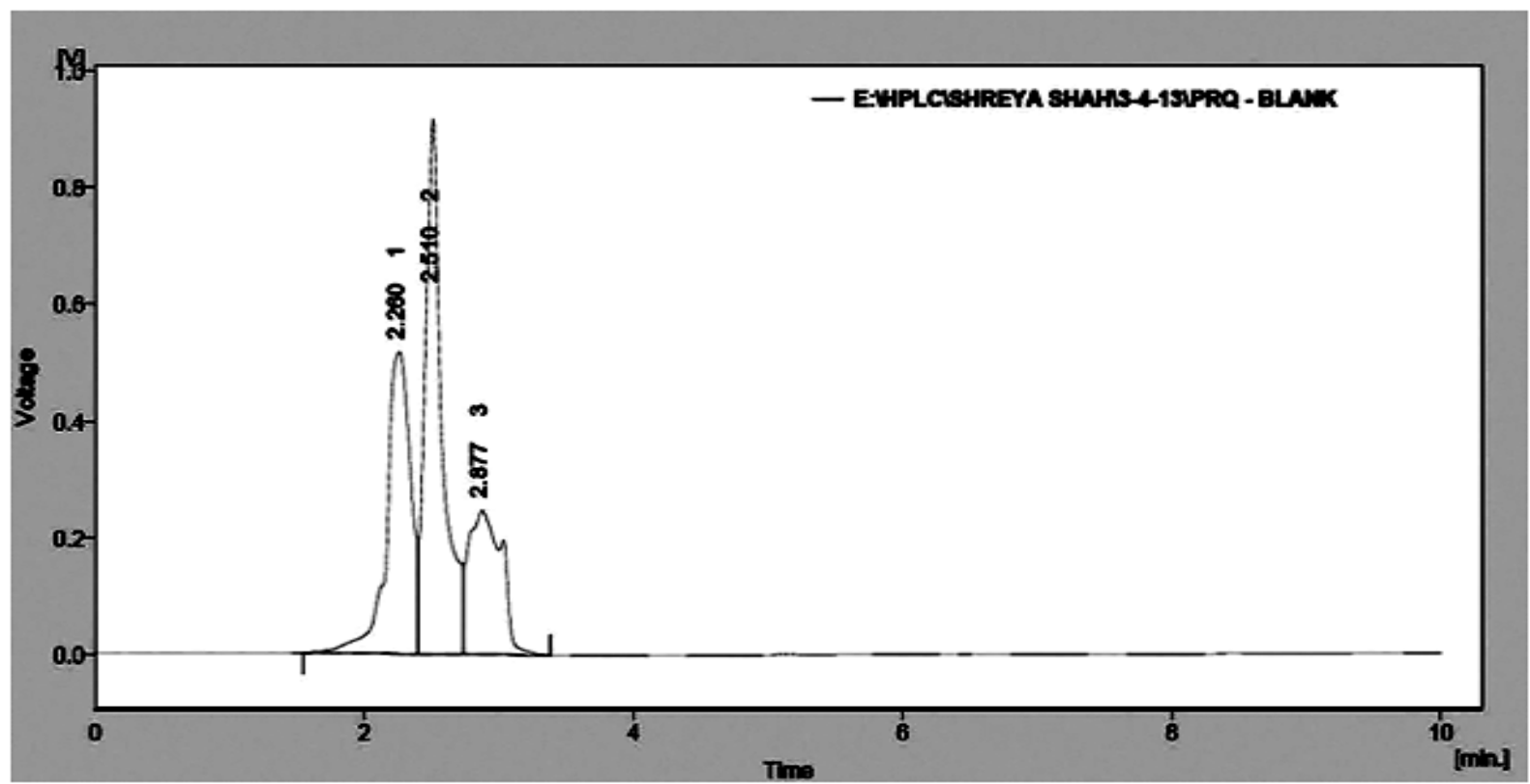

Fig 6. Chromatogram of blank rat plasma without albendazole, praziquantel

Any potential interference [overlapping peaks] due to plasma endogenous components were within 2-3 min only [Figure 7], later, there was no significant interference from blank plasma that affected the response of ABZ, PRQ and Diazepam and an overlay chromatogram of all concentrations of ABZ, PRQ, Diazepam in plasma [Figure 8]. 

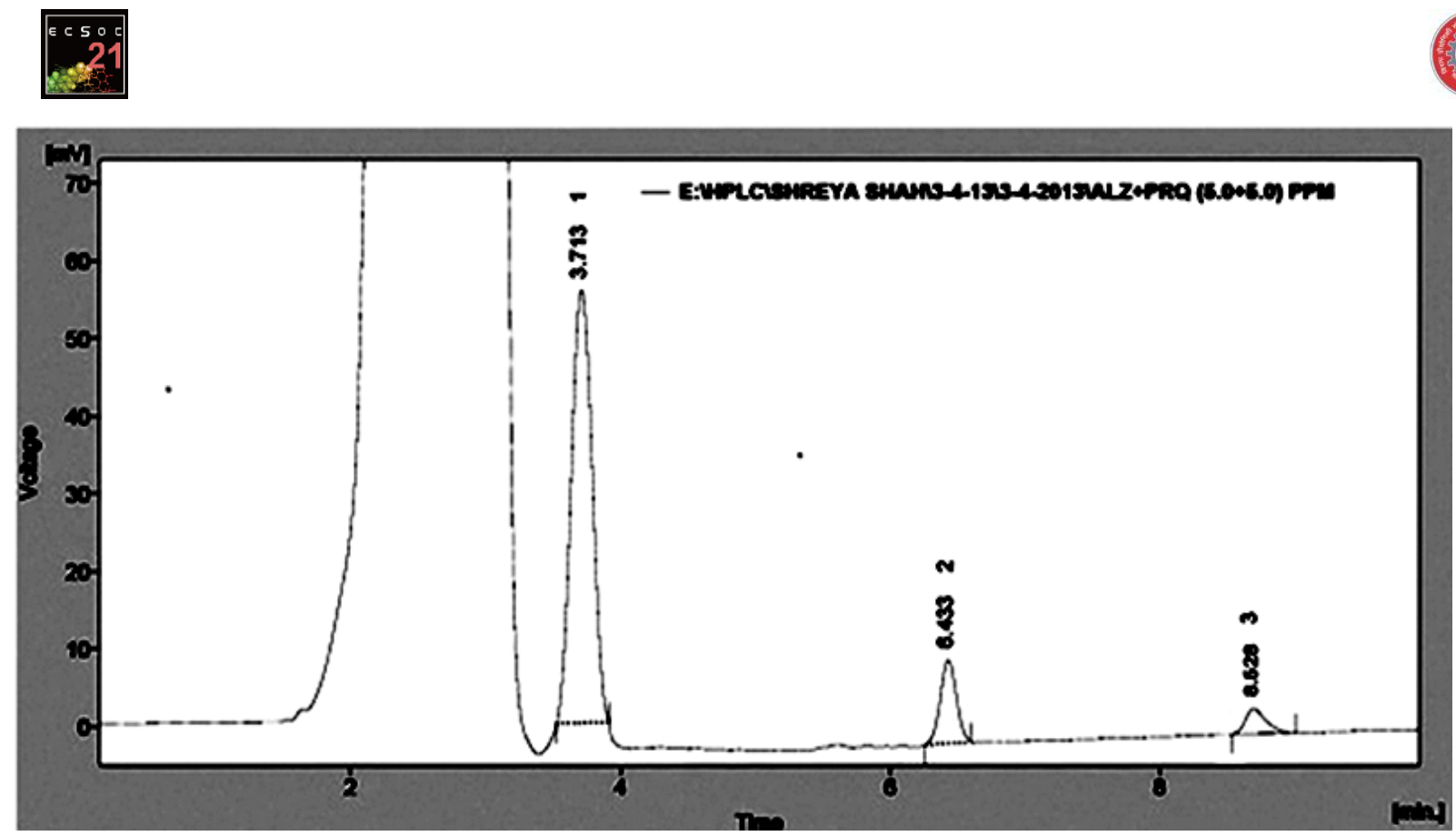

Fig 7. Chromatogram of standard solution of albendazole, praziquantel $(5000 \mathrm{ng} / \mathrm{ml}) \&$ diazepam $(500 \mathrm{ng} / \mathrm{ml})$ in plasma with retention times of $3.7,6.4 \& 8.5$.

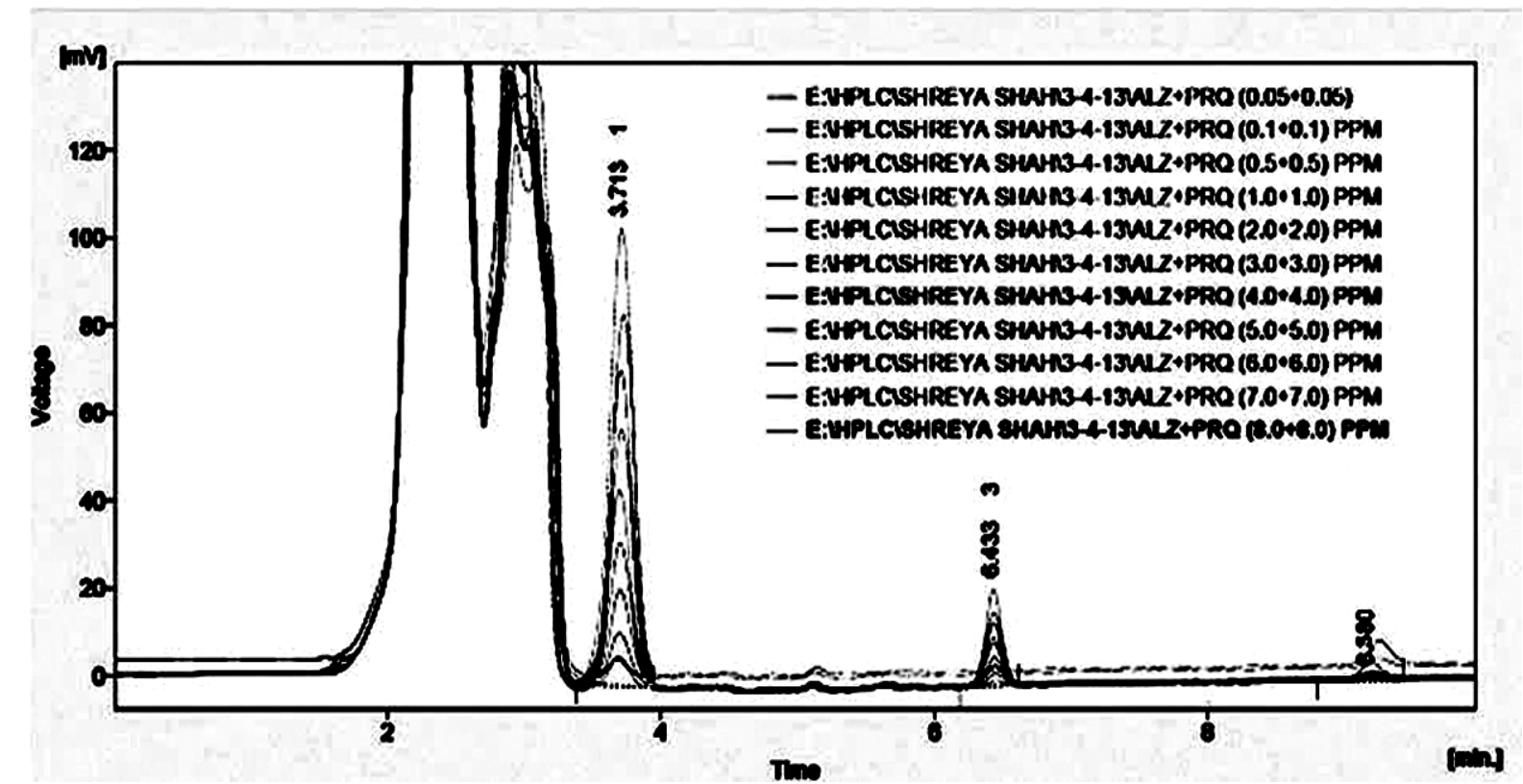

Fig 8. Overlay Chromatogram of standard solution of ABZ \& PRQ from 50-80000ng/ml with a fixed concentration of Diazepam $(500 \mathrm{ng} / \mathrm{ml})$ with retention time of $3.7,6.4 \& 8.5$ min.

\subsubsection{Limit of quantitation [LOQ] and Limit of Detection [LOD]}

The limit of quantitation [LOQ] in rat plasma for ABZ and PRQ was accepted as 50ng for both the drugs using $400 \mu \mathrm{L}$ of plasma.

The detection limit of an individual analytical procedure is the lowest amount of analyte in a sample, which can be detected but not necessarily quantified as an exact value. Limit of Detection [LOD] in rat plasma for ABZ and PRQ was 15.15ng. LOD can be calculated as given below. Therefore $\mathrm{LOQ}=3.3 * \mathrm{LOD}$ 


\subsubsection{Stability}

Plasma samples containing ABZ and PRQ at concentrations of 50,5000 , and $8000 \mathrm{ng} / \mathrm{mL}$ were found to be stable when stored in a $-20^{\circ} \mathrm{C}$ freezer for a minimum of 6 months without significant degradation of the drug. Long-term storage of the spiked samples for up to 6 months did not appear to affect the quantitation of the analytes. Mean deviation [\%] of measured concentrations after storage at the observed periods $\left[1^{\text {st }}, 2^{\text {nd }}, 4^{\text {th }}\right.$ and $6^{\text {th }}$ months $]$ varied between -4.80 to $2.06 \%$ for ABZ [Table 5a] and -6.33 to $3.80 \%$ for PRQ [Table 6a]. Freezing and thawing for three successive cycles did not affect the measured concentrations. Mean deviation from the theoretical values varied between 0.426 to $1.476 \%$ for ABZ [Table 5b] and 0.16 to 3.11 for PRQ [Table 6b].

Table 5a, 5b: Storage stability data of ABZ \& PRQ in plasma at concentrations 50, $5000, \& 80000 \mathrm{ng} / \mathrm{mL}$

\begin{tabular}{|c|c|c|c|c|c|c|c|}
\hline \multirow{2}{*}{$\begin{array}{c}\begin{array}{c}\text { Time period } \\
\text { (months) }\end{array} \\
\text { ABZ }\end{array}$} & \multirow{2}{*}{$\begin{array}{l}\text { Concentration } \\
\text { added }(\mathrm{ng} / \mathrm{mL})\end{array}$} & \multicolumn{6}{|c|}{ Concentration measured $(\mathrm{ng} / \mathrm{mL})$} \\
\hline & & Assay 1 & Assay 2 & Assay 3 & Mean & S.D & $\%$ DEV $^{\mathrm{a}}$ \\
\hline \multirow[t]{3}{*}{1} & 50 & 50.12 & 50.01 & 49.02 & 49.7167 & 0.60583 & -0.5667 \\
\hline & 5000 & 5002.15 & 4993.68 & 4984.42 & 4993.42 & 8.86835 & -0.1316 \\
\hline & 8000 & 7991.28 & 8002.56 & 8085.87 & 8026.57 & 51.6643 & 0.3321 \\
\hline \multirow[t]{3}{*}{2} & 50 & 49.19 & 49.96 & 50.14 & 49.7633 & 0.50461 & -0.4733 \\
\hline & 5000 & 4998.97 & 4962.42 & 4963.69 & 4975.03 & 20.7415 & -0.4995 \\
\hline & 8000 & 8220.42 & 8168.07 & 8168.28 & 8185.59 & 30.165 & 2.31985 \\
\hline \multirow[t]{3}{*}{3} & 50 & 48.35 & 46.32 & 48.12 & 47.5967 & 1.11159 & -4.8067 \\
\hline & 5000 & 4914.42 & 4903.69 & 4882.12 & 4900.08 & 16.4546 & -1.9985 \\
\hline & 8000 & 7948.14 & 7920.42 & 7942.41 & 7936.99 & 14.6336 & -0.7876 \\
\hline \multirow[t]{3}{*}{4} & 50 & 46.25 & 48.45 & 48.46 & 47.72 & 1.27307 & -4.56 \\
\hline & 5000 & 4914.42 & 4934.15 & 4954.68 & 4934.42 & 20.1283 & -1.3116 \\
\hline & 8000 & 7905.3 & 7890.04 & 7840.18 & 7878.51 & 34.059 & -1.5187 \\
\hline PRQ & & Assay 1 & Assay 2 & Assay 3 & Mean & S.D & $\% \mathrm{DEV}^{\mathrm{a}}$ \\
\hline \multirow[t]{3}{*}{1} & 50 & 52.3636 & 51.3269 & 52.0186 & 51.903 & 0.52791 & 3.80602 \\
\hline & 5000 & 5057.27 & 5019.1 & 5062.11 & 5046.16 & 23.5632 & 0.92321 \\
\hline & 8000 & 8161.91 & 8195.06 & 8109.86 & 8155.61 & 42.9473 & 1.94512 \\
\hline \multirow[t]{3}{*}{2} & 50 & 50.4777 & 51.0186 & 52.8213 & 51.4392 & 1.22712 & 2.87843 \\
\hline & 5000 & 5017.72 & 5005.86 & 5006.13 & 5009.91 & 6.77036 & 0.1981 \\
\hline & 8000 & 8024.21 & 8095.06 & 8131.91 & 8083.73 & 54.7353 & 1.04658 \\
\hline \multirow[t]{3}{*}{3} & 50 & 49.0961 & 50.3961 & 48.6102 & 49.3675 & 0.92333 & -1.2651 \\
\hline & 5000 & 5011.39 & 5001.86 & 5017.18 & 5010.14 & 7.73354 & 0.2029 \\
\hline & 8000 & 8024.21 & 8061.91 & 8035.53 & 8040.55 & 19.3434 & 0.50685 \\
\hline \multirow[t]{3}{*}{4} & 50 & 47.013 & 46.8711 & 46.6102 & 46.8315 & 0.20429 & -6.3371 \\
\hline & 5000 & 4910.27 & 4917.82 & 4927.27 & 4918.45 & 8.52244 & -1.631 \\
\hline & 8000 & 7902.86 & 7964.2 & 7922.87 & 7929.98 & 31.2798 & -0.8753 \\
\hline
\end{tabular}

$\% \mathrm{DEV}=$ deviation of single mean value from theoretical value $(\%)$

\subsection{Quality control}

Three validated analysts conducted the plasma analysis. A standard curve and quality control specimens were included in each analysis. Control samples with the nominal concentration of 50, 4000, 5000 and $8000 \mathrm{ng} / \mathrm{mL}$ of ABZ and PRQ were analyzed at the beginning and the end of the analytical run. All results were within the acceptable limit $[ \pm 20 \%$ of their respective nominal values]. 
6a \& 6b: Storage stability data of $\mathrm{ABZ} \& \mathrm{PRQ}$ in plasma at concentrations 50, 5000, \& $80000 \mathrm{ng} / \mathrm{mL}$

\begin{tabular}{|c|c|c|c|c|c|c|c|}
\hline \multirow{2}{*}{\multicolumn{2}{|c|}{\begin{tabular}{|c|c|}
$\begin{array}{c}\text { Time period } \\
\text { (months) }\end{array}$ & $\begin{array}{c}\text { Concentration } \\
\text { added (ng/mL) }\end{array}$ \\
\multicolumn{2}{|c|}{ Freeze and thaw stability } \\
\end{tabular}}} & \multicolumn{6}{|c|}{ Concentration measured (ng/mL) } \\
\hline & & Assay 1 & Assay 2 & Assay 3 & Mean & S.D & \% DEV \\
\hline \multirow[t]{3}{*}{$\mathrm{ABZ}$} & 50 & 50.23 & 50.27 & 50.14 & 50.2133 & 0.06658 & 0.42667 \\
\hline & 5000 & 5008.4 & 5028.12 & 5052.19 & 5029.57 & 21.9309 & 0.59131 \\
\hline & 8000 & 8082.04 & 8138.13 & 8178.59 & 8132.92 & 48.4842 & 1.6615 \\
\hline \multirow[t]{3}{*}{ PRQ } & 50 & 51.1988 & 53.0016 & 50.4777 & 51.5594 & 1.3 & 3.1188 \\
\hline & 5000 & 5006.13 & 5002.88 & 5015.86 & 5008.29 & 6.755 & 0.16586 \\
\hline & 8000 & 8044.6 & 8055.53 & 8038.58 & 8046.24 & 8.59048 & 0.57794 \\
\hline
\end{tabular}

a $\% \mathrm{DEV}=$ deviation of single mean value from theoretical value $(\%)$

\section{CONCLUSION}

This paper reports for the first time the simultaneous analysis of ABZ and PRQ in rat plasma by HPLC using UV detector. The method described here is simple, rapid, and reproducible.

The quantitation limits obtained using $400 \mu \mathrm{L}$ plasma was similar to those reported in the literature and were small enough for the method to be used in pharmacokinetic studies. The major advantage of this method when compared to the previously published methods is cost effectiveness due to the use of HPLC having UV detector and using perchloric acid as a protein precipitating agent, sample preparation which gives clear chromatogram and at the same time it is cost effective. This above-developed method can be applied for the estimation or determination of albendazole and praziquantel in rat plasma along with their pharmacokinetic studies.

\section{ACKNOWLEDGEMENTS}

The first author is grateful to the Principal of Sigma Institute of Pharmacy, Vadodara, Dr. U. M. Upadhayay and to the management team for the support and providing necessary chemicals and equipment for this research work.

\section{REFERENCES}

1. A. Flisser, E. Sarti, M. Lightowlers, P. Schantz, Neurocysticercosis: regional status, epidemiology, impact and control measures in the Americas, Acta Trop. 87 [2003] 4351.

2. O.M. Takayanagui, Therapy for neurocysticercosis, Expert Rev. Neurotherapeutics 4 [2004] 129-139.

3. O.H. Del Brutto, Neurocysticercosis, Semin. Neurol. 25 [2005] 243-251.

4. F. Polomares, G. Palencia, J.R. Ambrosio, A. Ortiz, H. Jung-Cook, Evaluation of the efficacy of albendazole sulphoxide and praziquantel in combination on Taenia crassiceps cysts: in vitro studies, J. Antimicrobial Chemotherapy 57 [2006] 482-488.

5. D.M. Guo, S.P. Xie, J.P. Jia, Therapeutic efficacy of praziquantel, albendazole and a combination of the two drugs in cysticercosis, Chinese Journal of Parasitology and Parasitic Diseases 21 [2003] 187-188.

6. M.I. Yasawy, M.A.A.L. Karawi, A.R.E. Mohamed, Combination of praziquantel and albendazole in the treatment of hydatid disease, Tropical Medicine and Parasitology 44 [1993] 192-194.

7. F. Cobo, C. Yarnoz, B. Sesma, P. Fraile, M. Aizcorbe, R. Trujillo, A. Diazde- Liaño, M.A. Ciga, Albendazole plus praziquantel versus albendazole alone as a pre-operative 
treatment in intra-abdominal hydatisosis caused by Echinococcus granulosus, Trop. Med. Int. Health 3 [1998] 462-466.

8. A.E. Mohamed, M.I. Yasawy, M.A. Al Karawi, Combined albendazole and praziquantel versus albendazole alone in the treatment of hydatid disease, Hepatogastroenterology 45 [1998] 1690-1694.

9. H.M. Ayles, E.L. Corbett, I. Taylor, A.G.A. Cowie, J. Bligh, K.Walmsley, A.D.M. Bryceson, A combined medical and surgical approach to hydatid disease: 12 years' experience at the Hospital for Tropical Diseases, London, Annals of The Royal College of Surgeons of England. 84 [2002] 100-105.

10. C.Villaverde, A.I. Alvarez, P. Redondo, J.Voces, J.L. Del Estal, J.G. Prieto, Small intestinal sulphoxidation of Albendazole, Xenobiotica 25 [1995] 433-441.

11. E.A. Formentini, O.N. Mestorino, E.L. Marĩno, J.O. Errecalde, Pharmacokinetics of ricobendazole in calves., J. Vet. Pharmacol. Ther. 24 [2001] 199-202.

12. O.M. Takayanagui, P.S. Bonato, S.A.C. Dreossi, V.L. Lanchote, Enantioselective distribution of albendazole metabolites in cerebrospinal fluid of patients with neurocysticercosis, Br. J. Clinical Pharmacology 54 [2002] 125-130.s

13. A. Goudah, Aspects of the pharmacokinetics of albendazole sulphoxide in sheep, Veterinary Research Communications 27 [2003] 555-566.

14. V.L. Lanchote, O.M. Takayanagui, F.H. Mateus, Enantioselective renal excretion of albendazole metabolites in patients with neurocysticercosis, Chirality 16 [2004] 520525.

15. K. Pengsaa, K. Na-Bangchang, K. Limkittikul, K. Kabkaew, K. Lapphra, C. Sirivichayakul, P. Wisetsing, C. Pojjaroen-Anant, P. Chanthavanich, A. Sbchareon, Pharmacokinetic Investigation of Albendazole and Praziquantel in Thai Children Infected with Giardia intestinalis, Ann. Trop. Med. Parasitol. 98 [2004] 349-357.

16. C. Lerch, G. Blaschke, Investigation of the stereoselective metabolism of praziquantel after incubation with rat liver microsomes by capillary electrophoresis and liquid chromatography-mass spectrometry, J. Chromatogr. B 708 [1998] 267-275.

17. H. Meier, G. Blaschker, Investigation of Praziquantel metabolism in isolated rat hepatocytes, Journal of Pharmaceutical and Biomedical Analysis 26 [2001] 409-415.

18. A. Godawska-Matysik, E. Pekala, K. Kiec-Kononowicz, The research on biotransformation of praziquantel, Acta Pol. Pharm. 61 [2004] 75-78.

19. U. Staudt, G. Schmahl, G. Blaschke, H. Mehlhorn, Light and scanning electron microscopy studies on the effects of the enantiomers of praziquantel and its main metabolite onSchistosoma mansoni in vitro, Parasitol. Res. 78 [1992] 392-397.

20. F. Westhoff, G. Blaschke, High-performance liquid chromatographic determination of the stereoselective biotransformation of the chiral drug praziquantel, J. Chromatogr. 578 [1992] 265-271.

21. M.E.C. Valois, O.M. Takayanagui, P.S. Bonato, V.L. Lanchote, D. Carvalho, Determination of Albendazole Metabolites in Plasma by HPLC, Journal of Analytical Toxicology 18 [1994] 86-90.

22. S.R. Polo, J. Torrado, F. Bolas, S. Torrado, A Selective and Simple RP-HPLC Assay To Quantify Albendazole Metabolites in Plasma Journal of Liquid Chromatography and Related Technologies, 21 [1998] 2327-2340.

23. J.J. Garcia, F. Bolas-Fernandez, J.J. Torrado, Quantitative determination of albendazole and its main metabolites in plasma., J. Chromatogr. B 723 [1999] 265-271.

24. A. Mirfazaelian, S. Dadashzadeh, M.R. Rouini, An HPLC method for determination of albendazole main metabolites, Pharmacy and Pharmacology Communications 6 [2000] 563-566. 
25. D. Kitzman, K.J. Cheng, L. Fleckenstein, HPLC assay for albendazole and metabolites in human plasma for clinical pharmacokinetic studies, Journal of Pharmaceutical and Biomedical Analysis 30 [2002] 801-813.

26. W. Ridtitid, M.Wongnawa,W. Mahatthanatrakul, J. Punyo, M. Sunbhanich, LC determination of praziquantel in human plasma. Journal of Pharmaceutical and Biomedical Analysis 28 [2002] 181-186.

27. A. Mirfazaelian, S. Dadashzadeh, M.R. Rouini, A high performance liquid chromatography method for simultaneous determination of albendazole metabolites in human serum, Journal of Pharmaceutical and Biomedical Analysis 30 [2002] 1249-1254.

28. R. Sarin, A.P. Dash, V.K. Dua, Albendazole sulphoxide concentrations in plasma of endemic normals from a lymphatic filariasis endemic region using liquid chromatography, Journal of Chromatography B 799 [2004] 233-238.

29. Z.Wu, N.J. Medlicott, M. Razzak, I.G. Tucker, Development and Optimization of a Rapid HPLC Method for Analysis of Ricobendazole and Albendazole Sulfone in Sheep Plasma, Journal of Pharmaceutical and Biomedical Analysis 39 [2005] 225-232.

30. A. Procha'zkova, M. Chouki, R. Theurillat, W. Thormann, Therapeutic drug monitoring of albendazole: Determination of albendazole, albendazole sulfoxide, and albendazole sulfone in human plasma using nonaqueous capillary electrophoresis, Eletrophoresis 21 [2000] 729-736.

31. H. Meier, G. Blaschke, Capillary electrophoresis-mass spectrometry, liquid chromatography-mass spectrometry and nanoelectrospray-mass spectrometry of praziquantel metabolites, Journal of Chromatography B 748 [2000] 221-231.

32. P.S. Bonato, V.L. Lanchote, O.M. Takayanagui, Simultaneous liquid chromatographytandem mass spectrometric determination of albendazole sulfoxide and albendazole sulfone in plasma, Journal of Chromatography B 783 [2003] 237-245.

33. X. Chen, L. Zhao, H. Xu, D. Zhong, Simultaneous determination of albendazole and its major active metabolite in human plasma using a sensitive and specific liquid chromatographic-tandem mass spectrometric method, Journal of Pharmaceutical and Biomedical Analysis 35 [2004] 829-836.

34. A.J.B. Melo, Y. Iamamoto, A.P.J. Maestrin, J.R.L. Smith, M.D. Santos, N.P. Lopes, P.S. Bonato, Biomimetic oxidation of praziquantel catalysed by metalloporphyrins, Journal of Molecular Catalysis A: Chemical 226 [2005] 23-31.

35. Pierina Sueli Bonato, Anderson Rodrigo Moraes de Oliveira, Fernando Jos'e Malague no de Santana, Bruno Jos'e Dumet Fernandes, Vera Lucia Lanchote, Armando E. Gonzalez, Hector H. Garcia, Osvaldo Massaiti Takayanagui, Simultaneous determination of albendazole metabolites, praziquantel and its metabolite in plasma by high-performance liquid chromatography-electrospray mass spectrometry, Journal of Pharmaceutical and Biomedical Analysis 44 [2007] 558-563

36. ICH Guidelines: Validation of Analytical Procedures: Q2[R1], 2005.

37. ICH Guidelines: Validation of Analytical Procedures: Q2A, 1994.

38. Guidance for the Industry: Analytical Method Validation, US Food and Drug Administration, Center for Drug Evaluation and Research [CDER], Rockville, MD, 2000.

39. S.N. Meyyanathan, G.V.S. Ramasarma, B. Suresh, Analysis of simvastatin in pharmaceutical preparations by high performance thin layer chromatography, ARS Pharma. 45 [2004] 121-129. 